\title{
Molecular Characterization of E 587 Antigen: An Axonal Recognition Molecule Expressed in the Goldfish Central Nervous System
}

\author{
SUZANNE GIORDANO, ${ }^{1}$ UTE LAESSING, ${ }^{1}$ RICHARD ANKERHOLD, ${ }^{1}$ \\ FRIEDRICH LOTTSPEICH, ${ }^{2}$ AND CLAUDIA A.0. STUE RME R ${ }^{1, *}$ \\ ${ }^{1} \mathrm{~F}$ aculty of Biology, U niversity of Konstanz, D-78434 Konstanz, Germany \\ 2Max Planck Institute for Biochemistry, Genzentrum, D-82152 Martinsried (F.L.), Germany
}

\begin{abstract}
The E587 antigen ( $\mathrm{Ag})$ is a $200-\mathrm{Kd}$ membrane glycoprotein originally identified by a monocl onal antibody on new and regenerating retinal ganglion cell axons in theadult gol dfish. We report the isolation of CDNAs encoding the E $587 \mathrm{Ag}$ and identify it as a member of the L1 family of cell adhesion molecules (CAMs). The predicted amino acid sequence of E587 Ag shows an approximately equal identity (40\%) to mouse L 1 , chick neuron-glia CAM, and chick neuron-glia-related CAM. Although the overall similarity is low, there is a high conservation of structural domains and specific sequence motifs.

Wholemount in situ hybridizations were performed on goldfish between 34 hours and 3 days postfertilization (pf). A dramatic increase in E587 Ag mRNA was observed between 34 and 48 hours pf. The expression of E587 Ag mRNA in neurons shortly precedes axonogenesis. A marked decrease in expression occurs by 3 days pf, when the axonal scaffold has already been established. Wholemount immunohistochemistry on embryos demonstrates expression of E587 Ag on all major tracts.

E587 Ag is absent from mature retinal ganglion cell axons, but its expression is induced by optic nerve transection. A corresponding induction of E587 Ag mRNA in retinal ganglion cells is shown by in situ hybridization. Furthermore, E587 Ag mRNA was detected in the optic nerve, which suggests that nonneuronal cells also express this molecule.

E587 Ag was previously shown to promote retinal axon fasciculation and outgrowth in young fish and to mediate axon-glial interactions in vitro. The expression pattern and devel opmental regulation of E587 Ag in the central nervous system, its reexpression in retinal ganglion cells following optic nerve transection, and its relation to the L 1 family indicate that E587 Ag functions as a cell recognition molecule important during axonal growth and regenera tion. J . Comp. Neurol. 377:286-297, 1997. @ 1997 Wiley-Liss, Inc.
\end{abstract}

Indexing terms: immunoglobulin superfamily; L1-family; cell adhesion molecule; axonal regeneration; CNS development

During central nervous system (CNS) development, axonal recognition molecules direct neurite outgrowth and guide axons along the appropriate path toward their targets. One family of neuronal recognition molecules is the L 1 family, which bel ongs to the larger immunogl obulin superfamily. Molecules belonging to the $L 1$ family have been identified in insects, fish, birds, and mammals (reviewed in Sonderegger and Rathjen, 1992; Brümmendorf and Rathjen, 1993). In vitro, these molecules effect neuronal outgrowth, axonal fasciculation, and cell adhesion (Brümmendorf and Rathjen, 1993). In the developing nervous system, molecules of the L 1 family are widely expressed, usually having overlapping but distinct expression patterns (Stallcup et al., 1985; Thiery et al., 1985; Krushel et al., 1993; Moscoso and Sanes, 1995). Recent

Contract grant sponsor: SBF 156; Contract grant sponsor: Alexander von Humboldt Foundation; Contract grant sponsor: Boehringer-Ingel heim-Fonds

*Correspondence to: Dr. C.A.O. Stuermer, Faculty of Biology, University of Konstanz, 78434 Konstanz, Germany.

E-mail: claudia-stuermer@uni-konstanz.de

Received 10 May 1996; Revised 13 September 1996; Accepted 24 September 1996 
results indicate that proteins of this family direct neuronal outgrowth in vivo and contribute to the orderly development of the nervous system (Stoeckli and Landmesser, 1995; Bastmeyer et al., 1995).

To identify molecules associated with axonal growth, we previously developed antibodies against membrane proteins expressed on regenerating retinal axons in the goldfish (Vielmetter et al., 1991). Goldfish retinal ganglion cell (RGC) axons functionally regenerate following injury, and growth-associated proteins are reexpressed during this process (reviewed in Stuermer et al., 1992). The E587 antigen ( $\mathrm{Ag}$ ) was originally identified in adult goldfish by the monodonal antibody (mAb) E587 as a protein associated with young growing axons that emerge from newly added RGCs during the continuous growth of the goldfish retina. This protein is also reexpressed on regenerating RGC axons foll lowing optic nervetransection (Viel metter et al., 1991). E587 Ag promotes axonal fasciculation of goldfish retinal axons and enhances growth cone velocities in vitro (Bastmeyer et al., 1995). In vivo, antibody perturbation experiments demonstrate that E587 Ag promotes the selective fasciculation of young, growing retinal axons (Bastmeyer et al., 1995), which results in the age-related ordering of these axons in the retina (E aster et al., 1984).

The results presented here identify E587 Ag as a member of the L1 family of cell adhesion molecules (CAMs). This family includes mammalian L 1 (human: Rosenthal et al., 1991; mouse: Moos et al., 1988; rat: Miura et al., 1991), chick neuron-glia (Ng)-CAM (Burgoon et al., 1991), neurofascin and neuron-glia-related (Nr)-CAM (Grumet et al., 1991; Vol kmer et al., 1992), Drosophila neuroglian (Bieber et al., 1989), and the recently cloned zebrafish L 1.1 and L 1.2 molecules (Tongiorgi et al., 1995). All these molecules, including the E587 Ag, sharestructural similarities, including six immunoglobulin (I g)-like domains and four or five fibronectin ( $\mathrm{Fn}$ ) typelll-like domains in their extracellular portions, a transmembrane region, and a highly conserved cytoplasmic domain. In most cases, the functional relationship of these molecules remains unclear. Sequence pair comparisons between E587 $\mathrm{Ag}$ and $\mathrm{L} 1$ and between $\mathrm{Ng}$ CAM and $\mathrm{Nr}$-CAM show an overall identity of only approximately $40 \%$ between E $587 \mathrm{Ag}$ and each of these molecules. Some regions of the molecules, however, are strongly conserved, and these domains may be structurally and functionally more important. In addition to isolating E587 Ag CDNAs, we demonstratethewidespread expression of E587 Ag mRNA and protein in the developing CNS and its mRNA upregulation in retinal ganglion cells following optic nerve transection.

A few CAMs, in addition to the E587 Ag, have now been identified in the CNS of teleost fishes (Laessing et al., 1994; Kanki et al., 1994; Tongiorgi et al., 1995; Warren et al., 1995). A detailed analysis of their structure and expression is the first step in evaluating the function of each molecule and how these molecules interact to form orderly CNS connections and contribute to successful axon regeneration. Furthermore, identification of CAMs from anamniotic vertebrates will help determine the relationship of these molecules in different species.

\section{MATERIALS AND METHODS Animals}

Goldfish were maintained in tanks at $18^{\circ} \mathrm{C}$, and embryos were obtained from a breeding col ony at the University of
Konstanz. Fish wereanesthetized in 0.03\% MS222 (Sigma, Deisenhofen, Germany) prior to optic nerve transections (ONS) and killed in accordance with animal welfare legislation. Some embryos were raised in $0.2 \mathrm{mM}$ 1-phenyl-2thiourea (PTU; Sigma) to prevent pigmentation. Embryos were staged according to Honma (1960) in hours and days postfertilization (pf).

\section{Protein purification and amino acid sequencing}

Proteins from adult goldfish brains were solubilized in octylglucoside, and E587 Ag was immunopurified over an antibody affinity column (E587 mAb) as described by Vielmetter et al. (1991). N-terminal and internal peptide sequences were obtained following the procedure described for neurolin, another goldfish membrane protein previously identified in this laboratory (Laessing et al., 1994).

\section{I solation of CDNAs}

Degenerate primers corresponding to peptide sequences obtained for the E587 Ag were synthesized for use in the polymerase chain reaction (PCR). Total RNA was isolated from embryonic goldfish with RNazol B (Biotech Labs, USA) and first-strand CDNA template was primed with oligo dT18.

Initially, primers P1 (5'-ACT(C)TGA(G)TCT(C)TCT(C)TCT(C)TT-3)' and P2 (5'-AAT(C)CCICCITTT(C)ATIGT-3') were used for PCR at an annealing temperature of $48^{\circ} \mathrm{C}$. These primers correspond to the peptide sequences SSNPPFIV (aa 735-741) and DKEEDQ (aa 1123-1129) and have homol ogy with sequences in the $\mathrm{C}$-terminal region of mammalian L1 and chick Ng-CAM as determined by computer analysis. The PCR produced a $1.2-\mathrm{Kb}$ band that was cloned into the TA cloning vector, pCR II (I nvitrogen, USA) and sequenced by using the T7 Sequencing Kit (Pharmacia Biotech, Germany). This fragment (done 1) was isolated, labeled with ${ }^{32}$ P-dATP (Random priming kit, $B R L$ ), and used to screen a goldfish embryonic CDNA library. This lambda Zap II (Stratagene) library was synthesized by using mRNA isolated from 5-day-old goldfish, and the first strand was primed with oligo dT. Hybridization was carried out in Quik Hyb (Stratagene) at $68^{\circ} \mathrm{C}$, and filters were washed at the same temperature with a final wash in $0.1 \times$ sodium-saline-phosphate-EDTA buffer (SSPE) and $0.1 \%$ sodium dodecylsulfate (SDS). A 2.8-K $\mathrm{b}$ fragment (clone 2 ) was obtained that included the previously sequenced $1.2-\mathrm{Kb}$ fragment of clone 1 . A 200base pair (bp) restriction enzyme fragment from the $\mathrm{N}$ terminus of clone 2 was used to screen a random primed lambda Zap II cDNA library made from retina mRNA 14 days after ONS. Screening was carried out at the same conditions described above. A 3.8-Kb done (clone 3) was isolated from this screen. Restriction fragments of this clone were subcloned, and the entire cl one was sequenced on both strands from the ends of these fragments and with specific primers for internal sequences. The $\mathrm{N}$-terminal done 4 was obtained by PCR by using the spedific primer P6 (5'-(GATGCACTCTAGAGTCAG)-3)', which corresponds tothe sequence LTLECI (aa 229-234), and a degenerate primer corresponding to an $\mathrm{N}$-terminal peptide sequence M MPPDYT, P5 (5'-(ATIATICCICCI GAT(C)TAT(C)AC)-3)'.

PCR was also performed on CDNA templates synthesized from optic nerve total RNA. Total RNA was isolated 
EXTRACEUULAR DOMAN

\section{CYTOPLASMIC \\ DOMAN}

Ig domains Fn type III domains
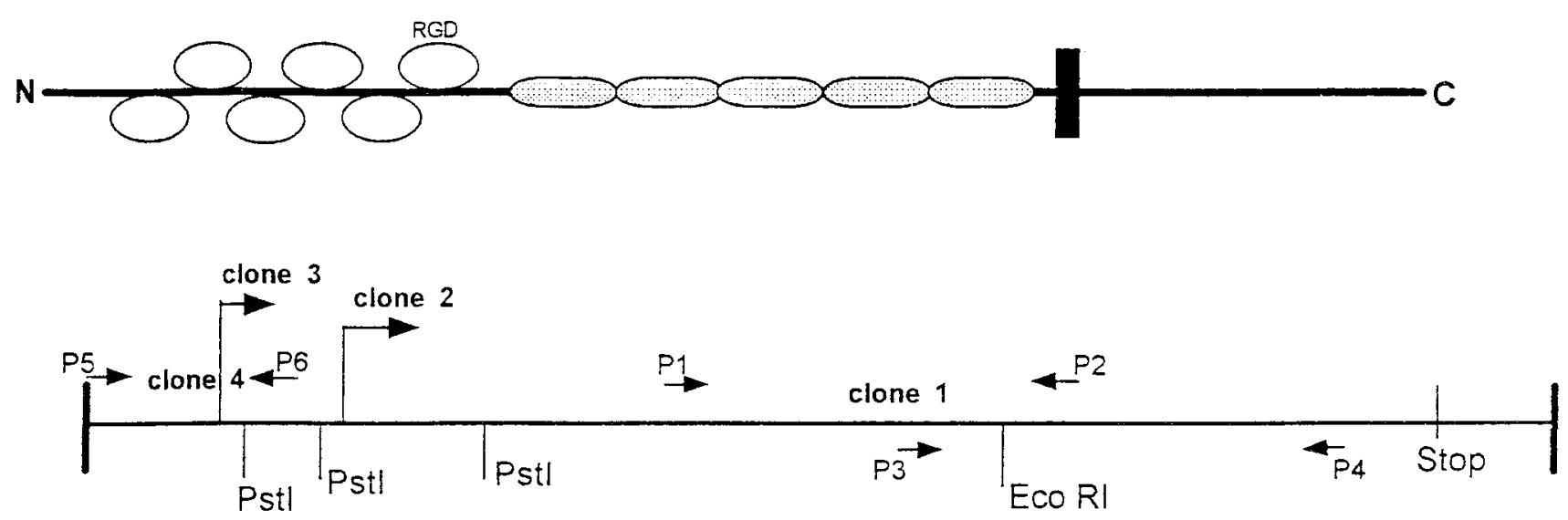

Fig. 1. Cloning strategy. The upper diagram shows the structure of the L1 family of cell-adhesion molecules (CAMs). The diagram below represents the E587 antigen (Ag) CDNAs. The Pstl and EcoRI restriction sites are indicated. $\mathrm{P} 1$ and $\mathrm{P} 2$ are the original primers used for polymerase chain reaction (PCR). P3 and P4 were used to isolate optic

from normal adult optic nerves or optic nerves 13 days after ONS. PCR was carried out with primers P3 (5'TATACACTGACAGTTGCA-3') and P4 (5'-AACACTGTCTCCGTAGTCGGC-3') at an annealing temperature of $60^{\circ} \mathrm{C}$ (Fig. 1). The $0.940-\mathrm{Kb}$ band was subcloned and sequenced as described above.

Sequence analysis was done with the Wisconsin $\mathrm{Se}$ quence Analysis System, version 8. Comparisons were done using the GAP program (Genetics Computer Group, Wisconsin, USA).

The E587 Ag cDNA sequence can be found in the Genbank under the accession number U55211.

\section{Riboprobes and in situ hybridization}

The $\mathrm{pCR}$ II vector containing the 1.2-Kb clone 1 was linearized with either $\mathrm{Xhol}$ or $\mathrm{Kpnl}$ for the synthesis of antisense and sense probes, respectively. Digoxigenin (DIG)-labeled riboprobes were synthesized with the DIGlabeling kit as outlined by the manufacturer (Boehringer Mannheim, Germany). In situ hybridization (ISH) on whole goldfish embryos was performed essentially as described by Laessing and Stuermer (1996), except color development was carried out in the BM-purple substrate (Boehringer Mannheim). All embryos were viewed as wholemounts, and some embryos were subsequently embedded in Durcupan AMC (Fluka) for sectioning.

ISH was also performed on wholemounted retina of adult gol dfish, both normal and at 14 days after optic nerve transection. In this case, the PCR II vector containing the clone was linearized with Hind III for the synthesis of sense probes. Both antisense and sense probes were hydro- nerve cDNAs. The longest clone, clone 3, begins at the second immunoglobulin ( $\mathrm{Ig}$ ) domain and includes the remaining coding sequence, including the stop codon. P5 and P6 were used to isol ate the $\mathrm{N}$-terminal CDNA, clone 4. RGD, arginine-glycine-aspartic acid.

lyzed to a length of approximately 250 bp to improve tissue penetration. Essentially the same protocol used for goldfish embryos was applied except that the hybridization was carried out overnight in a waterbath at $55^{\circ} \mathrm{C}$. Retina whol emounts were prepared as described by Vielmetter et al. (1991), flattened out on Hybond-N + filters (Amersham), fixed in $4 \%$ formaldehyde, and taken through thein situ hybridization protocol. The retinas were removed from their filters, mounted on slides, and photographed under Nomarski optics.

\section{Immunohistochemistry}

Embryos were incubated for 10 seconds in methanol $\left(-20^{\circ} \mathrm{C}\right)$ and then fixed overnight in buffered fixative $(4 \%$ paraformaldehyde, $4 \%$ sucrose, $0.1 \mathrm{M}$ sodium phosphate, pH 7.4). After two washes in phosphate buffered saline (PBS) and one in distilled water (10 minutes each), embryos were permeabilized in acetone $\left(7 \mathrm{~min}\right.$ at $\left.-20^{\circ} \mathrm{C}\right)$ and then washed twice in $\mathrm{H}_{2} \mathrm{O}$ and once in PBS. To reduce autofluorescence, embryos were incubated $3 \times 10$ minutes each in $10 \mathrm{ml}$ PBS with the addition of a small crystal of sodium borohydride. Embryos were blocked for 2 hours at $37^{\circ} \mathrm{C}$ in blocking buffer [1× PBS with $1 \%$ bovine serum al bumin (BSA), $1 \%$ dimethylsulfoxide (DMSO), $2 \%$ donkey serum], and then incubated in an anti-E587 Ag mAb (15 $\mu \mathrm{g} / \mathrm{ml}$ in blocking buffer) overnight at $4^{\circ} \mathrm{C}$. After washes ( $3 \times 15$ minutes in blocking solution without serum), embryos were incubated in cyanin-3-coupled donkey antimouse secondary antibody (Dianova) diluted to $0.45 \mu \mathrm{g} / \mathrm{ml}$ in blocking solution. Embryos were washed as above and embedded on slides in mowiol/n-propylgallate. 
TABLE 1. Percentage of Amino Acid I dentity Between E587 Ag and Other Cell-Adhesion Molecules (CAMs) ${ }^{1}$

\begin{tabular}{|c|c|c|c|c|c|c|c|c|c|c|c|c|}
\hline CAM & Ig-I & $|g-I|$ & $|g-|||$ & Ig-IV & Ig-V & Ig-VI & Fn-1 & $\mathrm{Fn}-2$ & $\mathrm{Fn}-3$ & $\mathrm{Fn}-4$ & $\mathrm{Fn}-5$ & C-Tail \\
\hline $\mathrm{mL} 1$ & 41 & 44 & 42 & 50 & 35 & 30 & 44 & 42 & 40 & 42 & 27 & 62 \\
\hline ZL 1.1 & - & 75 & 68 & 79 & 66 & 66 & 58 & 66 & 54 & 57 & 59 & 78 \\
\hline NgCAM & 38 & 45 & 41 & 51 & 42 & 26 & 36 & 45 & 33 & 29 & 29 & 59 \\
\hline NrCAM & 33 & 39 & 40 & 45 & 25 & 35 & 52 & 50 & 39 & 34 & 30 & 48 \\
\hline zL 1.2 & - & - & - & - & - & - & - & - & - & - & - & 50 \\
\hline $\mathrm{dNg}$ & 29 & 26 & 24 & 37 & 32 & 34 & 26 & 34 & 29 & 32 & 21 & 39 \\
\hline
\end{tabular}

${ }^{1} \mathrm{~A}$ comparison was carried out between individual domains of the E $587 \mathrm{Ag}$ and those of other members of the L1 family. An amino acid identity of $50 \%$ or higher appears in boldface type. Ig, immunoglobulin domains; Fn, fibronectin type-lII domains; C-Tail, transmembrane region and cytoplasmic domain; mL 1, mouse L 1 (Moos et al., 1988); zL 1.1 and zL 1.2, zebrafish (Tongiorgi et al., 1995); dNg Drosophila neuroglian (Bieber et al., 1989); Ng-CAM and Nr-CAM, chick (Burgoon et al., 1991; Grumet et al., 1991).

\section{Northern blots}

Total RNA was isolated from 3-day-old goldfish and adult whole brains with RNazol B (Biotec Laboratories, USA). Twenty micrograms of total RNA were separated on $1 \%$ denaturing agarose gel and transferred to a nylon membrane (Stratagene). Membranes were prehybridized for 1 hour at $55^{\circ} \mathrm{C}$ in Quik Hyb solution (Stratagene). 32P-labeled riboprobes were synthesized from the original 1.2-Kb PCR fragment and purified through Stratagene push columns. Hybridizations were carried out overnight at $55^{\circ} \mathrm{C}$, and blots were subsequently washed as follows: rinse once, room temperature in $2 \times$ SSC, $0.1 \%$ SDS; wash twice, 20 min $55^{\circ} \mathrm{C}$ in $1 \times$ standard saline citrate (SSC), $0.1 \%$ SDS, wash once, 20 minutes, $55^{\circ} \mathrm{C}$ in $0.2 \times \mathrm{SSC}, 0.1 \%$ SDS. Membranes were exposed to X-OMAT 5AR film (Kodak) for 3 days at $-70^{\circ} \mathrm{C}$.

\section{RE SULTS Cloning of goldfish E 587 cDNAs}

E587 Ag aminoacid sequence was obtained from sequencing peptide fragments of the immunopurified protein. A computer search of two of the peptide sequences showed homologies to the C-terminal region of mamalian L1 proteins (Moos et al., 1988). PCR was carried out with the degenerate primers $\mathrm{P} 1$ and $\mathrm{P} 2$, corresponding to partial sequences of these two peptides (Figs. 1, 2). The amplification produced a 1.2-K b band (clone 1). The predicted amino acid sequence encoded the entire sequences of the two corresponding peptides and an open reading frame (ORF) of 400 amino acids. A computer search reveal ed the highest homologies with members of the L 1 family of cell adhesion molecules. Two screenings of different cDNA libraries were subsequently performed to obtain larger E 587 Ag cDNAs. Screening of a goldfish embryonic cDNA library resulted in the isolation of a 2.8-Kb clone, clone 2, which included the entire sequence of the original PCR fragment. In addition, this clone encoded 68 amino acids upstream of clone 1 , the entire $C$ terminus of the protein including the stop codon (taa), and 1,100 bp of 3' noncoding sequence. The second screen was carried out on a random primed library synthesized from retina mRNA isolated 2 weeks after ONS. One clone of $3.8 \mathrm{~Kb}$, clone 3 , was isolated (Fig. 1). This clone encoded an ORF of 1,095 amino acids, which included the entire coding sequence contained in clone 2 and 540 amino acids of additional $\mathrm{N}$-terminal sequence that encodes up to the middle of the second Ig domain. The $\mathrm{N}$-terminal piece of E587 Ag was obtained by PCR (clone 4). This clone contains sequences that overlap with clone 3 and $390 \mathrm{bp}$ of additional sequence encoding the first two I $g$ domains. The sequence encoding the signal sequence is not included in this cl one (Fig. 2).
That these CDNAs encode the E587 Ag was confirmed by the alignment of the predicted amino acid sequence with those obtained from amino acid sequencing of the purified protein. All peptide sequences exactly match the amino acid sequence predicted from the CDNA (Fig. 2). Analysis with the Fasta program showed that this sequence has the highest similarity with mouse LI (Moos et al., 1988), with an identity of $40 \%$.

The E $587 \mathrm{Ag}$ cDNA encodes a transmembrane protein of 1,232 amino acids, with an extracellular domain consisting of six Ig domains and five $\mathrm{F} n$ type-lll domains (Fig. 2). This structure is common to all L1 family members (Brümmendorf and Rathjen, 1993). The cytoplasmic domain contains 121 amino acid residues. The predicted molecular weight is $136 \mathrm{Kd}$. The observation of a $200-\mathrm{Kd}$ band on Western blots (Vielmetter et al., 1991) can be accounted for by posttranslational modifications. Theextracellular domain of the predicted protein has 13 potential sites for $\mathrm{N}$-linked glycosylation, and the E587 Ag carries the HNK-1 epitope (Vielmetter et al., 1991).

\section{Sequence similarities in members of the L 1 family}

The predicted amino acid sequence of E587 Ag was compared with several molecules of the $L 1$ family. The comparison reveals a limited degree of homol ogy between E587 Ag and other L1 family members. E587 Ag has an overall identity of approximately $40 \%$ with several molecules, including mouse L1 (Moos et al., 1988), chick Ng-CAM (Burgoon et al., 1991), and chick N r-CAM (Grumet et al., 1991). I ts identity is 31\% identical to the Drosophila protein neuroglian (Bieber et al., 1989). Recently, two L1-related molecules were partially cloned in the zebrafish (Tongiorgi et al., 1995). E587 Ag is most related to the L 1.1 molecule (65\% identity); however, only the C-terminal region of the L1.2 molecule has been cloned.

Sequence comparisons between E587 Ag and other L1 family members reveals sequences that are conserved between molecules of different species. The most highly conserved domain is the cytoplasmic tail. The cytoplasmic regions of $E 587 \mathrm{Ag}$, mouse $L 1$, and zebrafish $L 1.1$ are $86 \%$ identical (Table 1). The C-terminal domain contains several potential phosphorylation sites and a conserved sequence that is characteristic of ankyrin binding proteins (aa 1182-1198). When individual domains are compared, the greatest similarity is found between the fourth Ig domain of the different family members. Interestingly, this domain contains a stretch of amino acid residues (AAPYW), conserved in all L1-family members, which may be involved in interactions with the fibroblast growth factor receptor (FGFR; Williams et al., 1994). The sixth Ig domain of the E587 Ag contains an RGD sequence that 


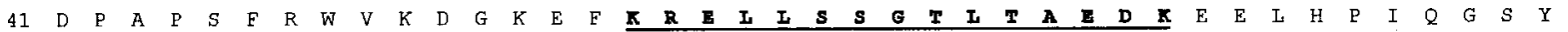

121 gacccggcacccagcttccgctgggtgaaagatggcaaagagtttaagagggaactgttgagttcgggaactctgacagcagaagataagaggagctccatcctatccagggatcgtac

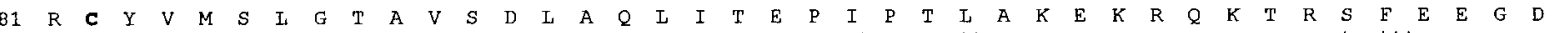

21 cgctgctacgtgatgagcttgggaaccgccgtctcagacctggcgcagctgatcacagagcccatcccaaccttggccaaagagaagaggcagaaaacaagatcgtttgaggagggagac

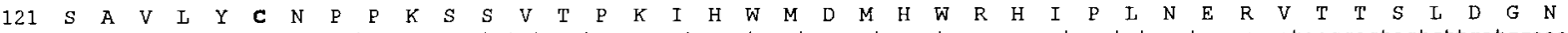

361 agcgcagtcctctactgtaaccctcccaagagctctgtcactcccaaaatacactggatggacatgcactggegccacatccctctgaatgagcgggtgaccactagtcttgatggaaat

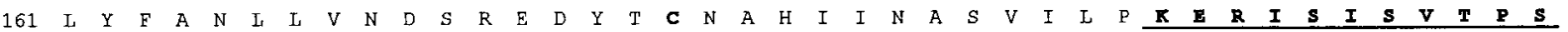

481 ctgtactttgccaacttactagtcaatgacagcagagaagactacacctgcaatgcccacatcatcaacgccagcgtcatcctccctaaagagcgcatctecatcagcgtcacacctct

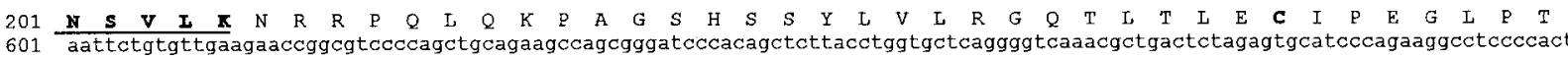

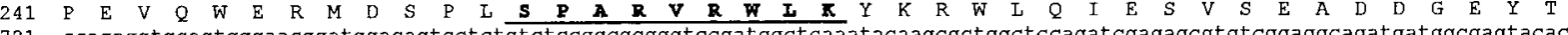

721 ccagaggtgcagtgggaacggatggacagtcctctgtctccggcgegggtccgatggctcaaatacaagcgctggctccagatcgagagcgtgtcggaggcagatgatggcgagtacaca

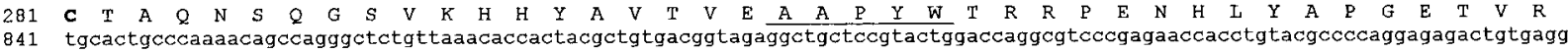

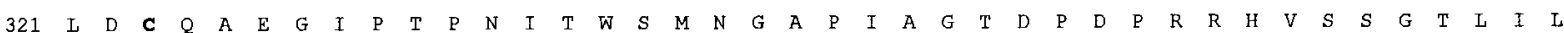

961 ctggactgtcaggctgaggggattcccaccccaaacatcacatggagcatgaacggcgctcccatcgcagggacagacccggacccgagacggcatgtgagctcagggacactgatcctg

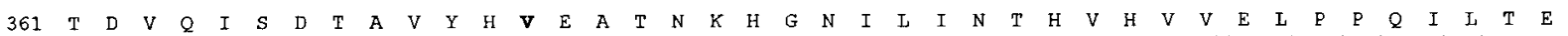

1081 actgacgttcagatcagcgatacggcggtctatcatgtcgaggccaccaataaacacggcaatatcctgatcaacacacatgtccatgtagttgagctgcctcctcagatcctgacagaa

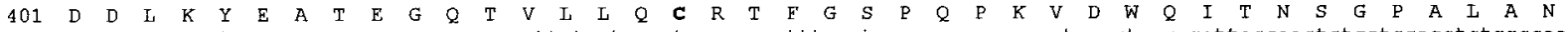

1201. gacgatctcaagtacgaggccacagaagggcaaacggttctgctgcagtgccgcacgtttggctecccacaacccaaagtcgactggcagattaccaactctggtecagetetggccaat

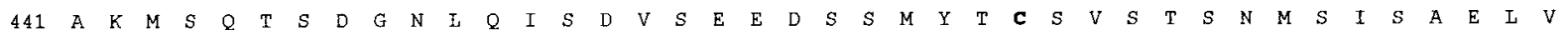

1321 gctaaatgtctcagacgagcgatggaaatcttcagatcagtgacgtgagtgaagaggacagcagcatgtacacgtgctcagtgagcaccagcaacatgagcatcagtgctgagctggtg

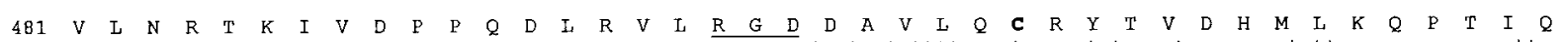

1441 gtcttgaacagaactaagattgtggaccctcctcaggacctgegggttttacgaggagatgatgetgttttgcagtgcagatatacagtggaccacatgttaaaacaacccacaattcag

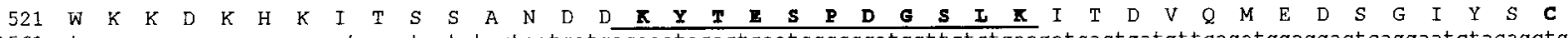

1561 tggaagaaggacaaacacaagatcacatcatctgctaatgatgacaaatacactgaatccccogatggttctctgaagatcactgatgttcagatggaggactcaggaatctacagctgt

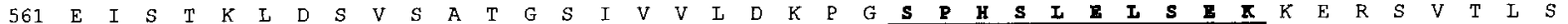
1681 gagatcagcactaaactggactcggtcagcgctaccggctccatcgttgttctggataagcccggttctcctcactctctggagctgtctgaaagaaggaacgtagtgtcacgttgtcc

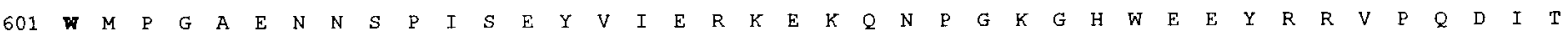

1801 tggatgccaggcgctgaaaacaacagtcctatatctgagtatgttattgagaggaaagagaagcagaatccaggaaagggccactgggaggagtacagaagagttcctcaagacatcaca

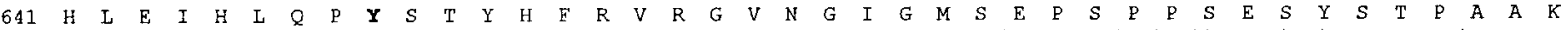

1921 cacctggagatccacctgcagccatacagcacttatcacttccgggtcagaggggtcaatggcataggaatgagtgagcccagtcctccttcagagtcatacagcacgcctgcagccaaa

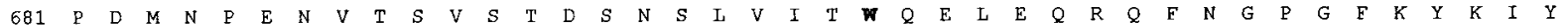

2041 cctgacatgaatccagagaatgtgacatcagtgtcgactgattcgaacagtctggtcatcacatggcaggaactggagcaacgacaatttaatgggccaggttttaagtacaagatctac

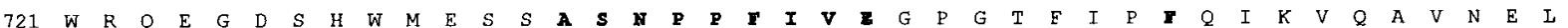

2161 tggcgtcaagaaggggattcacattggatggaaagcagtgcctcaaatcctccattcattgtggagggacccgggaccttcatccccttecagattaaagttcaggcagtcaatgagctt

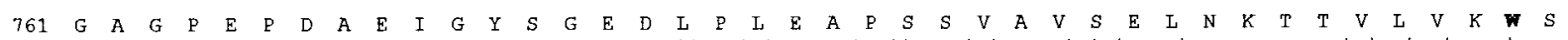

2281 ggtgcaggaccagaaccagatgctgagatcggttactcaggggaagacttacctctggaagctccttcaagtgtcgcagtgtctgagctgaacaaaaccactgtcctggtcaaatggagt

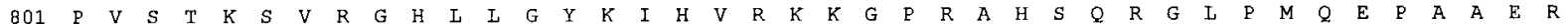

2401 ccagtcagcaccaaatctgtccgtggacacttacttggctacaagatccatgtgagaaagaaaggccccagagctcacagccaaagaggcctgccgatgcaagaaccagcagcagaacgg

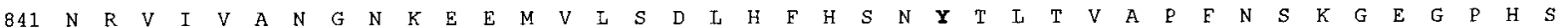
2521 aacagagtgattgtggctaatggaaataaggaggagatggtcttgagcgatttgcatttcactcgaactatacactgacagttgcacctttcaacagcaaaggtgaaggtccgcattcg

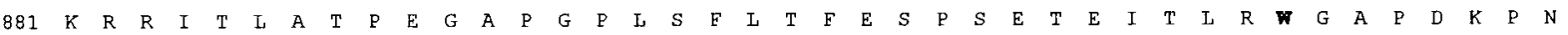

2641 aaacggcgtatcactttagcaactccagagggcgctcctggaccactttcattcttgaccttcgaaagcccatctgagacggagataaccctgcgctggggagctccagacaaacccaac

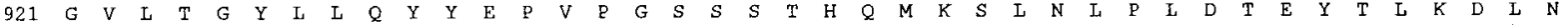

2761 ggagtgctcacaggatacctgctccagtactatgaacctgtgcctggaagttcgagcacacaccagatgaagtccctcaacctgcccettgatactgagtacactctgaaggatttgaat

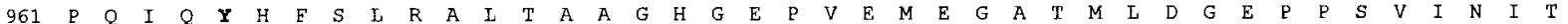
2881 cctcagatccaataccacttcagtetcagagcactcactgccgetggtcatggggagcecgtagaatggagggtgccaccatgttggatggagaaccaccatctgtaatcaacatcaca

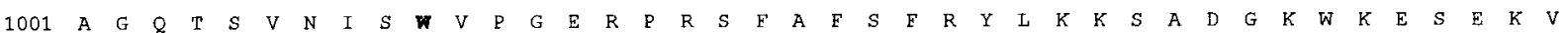

3001 getggacaaacatcggttaacatcagttgggtgccaggagaaagacccogtagctttgcctttagcttccgttacctgaaaaaagtgcggatggtaaatggaaagagtccgaaaggtc

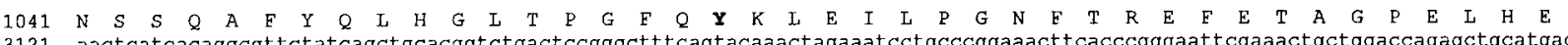

3121 aactcatcacaggcgttctatcagctgcacggtctgactccgggetttcagtacaaactagaaatcctgcccggaaacttcacccgggaattegaaactgctggaccagagctgcatgag

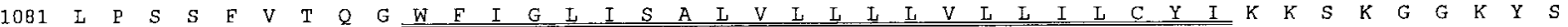

3241 ttgcccagcagcttgtaactcagggctggttcatcggactcatcagcgcettggttctgcttetgctggtgctgctcattctgtgctacatcaagaagagcaagggaggaaatattca

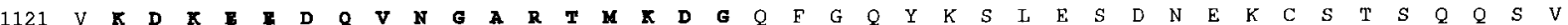

3361 gtgaagataaagaggaggatcaggtcaatggggccetacaatgaaagatggacagtttggacagtacaatetetggagagtgataacgagaagtgctccaccagtcagcagtctgtc

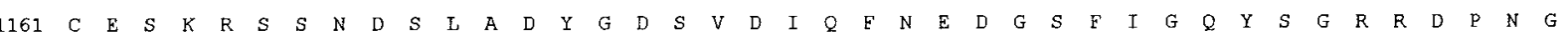

3481 tgcgagagcaagcgcagcagcaatgacagtctagccgactacggagacagtgttgacatccagtttaatgaggacggctccttcattggccagtacagtggacgcagagatccaaatggt

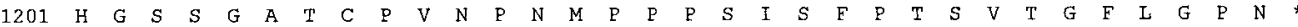

3601 cacggcagctcgggcgccacatgtcccgtcaatcccaacatgcctccacccagcatcagctttcccacgtctgtgacaggattcctggggecaaactaacgctccacctgtacacacaca

3721 cattcttgaccatttgaatgagggtcctgatggtattagacaggatattaatttcaggacagacagtcgttactatatgac 3801

Fig. 2. CDNA sequence of the goldfish $E 587 \mathrm{Ag}$ and predicted amino acid sequence of the E587 Ag. The E $587 \mathrm{Ag}$ cDNA encodes a transmembrane protein of 1,232 amino acids with I g-like and fibronectin type III (F nI II)-like domains. The cystein residues of the I g-like domains (and one valine at aa 373) and the tryptophan and tyrosine residues (and one phenylalanine at aa 750) of the Fnlll-like domains in the extracellular portion are in boldfacetype. Thetransmembrane domain has double underlines. Amino acid sequences obtained from protein analysis are in boldface type and underlined. The RGD sequence in the sixth Ig domain is underlined. The sequence encodes a protein of 1,232 amino acids ending at the stop codon, taa, at nucleotide 3685 
may be involved in integrin binding (Hynes, 1987). The RGD sequence is present in the samelocation in the mouse L1 protein (Moos et al., 1988) but is not found in the zebrafish L1.1 molecule (Tongiorgi et al., 1995). In the extracellular domains, the Ig domains and $\mathrm{Fn}$-III domains as a whole show similar degrees of identity between the different molecules. Different domains of the E587 Ag, however, are more closely related to the corresponding domains of different molecules and so it is difficult to determine the exact relationship between E587 Ag and other L 1 family members (see Table 1 and Discussion).

Northern blots detected two messages of approximately 7 and $8 \mathrm{~kb}$ in 3-day-old embryos and in adult brain. The presence of two messages suggest that there may be alternate splicing of the E587 Ag mRNA, although we found no other evidence of this from the isolated CDNAs.

\section{E $587 \mathrm{Ag}$ and its MRNA are expressed in the embryonic CNS}

Widespread expression of E587 Ag mRNA was observed in CNS neurons of goldfish embryos by ISH. ISH was performed at 34 hours, 48 hours, and 3 days. At 34 hours pf (Fig. 3), message is detected in the olfactory placode and the tel encephal on, in the diencephal on and the ventrocaudal cluster (the nudeus of the medial longitudinal fascicle), in the mesencephal on, in the trigeminal nucleus, in hindbrain and spinal cord commissural neurons, and in some (probably primary) motoneurons. No message was detected in floor plate cells, which in zebrafish show expression of $L 1.2$ (Tongiorgi et al., 1995). The onset of mRNA expression occurs at the time when these neurons begin to extend axons. At 48 hours pf (Fig. 4), many more neurons strongly express E 587 Ag mRNA, including commissural neurons in the hindbrain and spinal cord, and many neurons in the cerebellum, in the mesencephaIon including the developing optic tectum, diencephalon, and telencephalon. The trigeminal nucleus, neurons of the cranial nerve $V$, and the anterior and posterior lateral line ganglia are all strongly positive for E587 Ag mRNA. In the eye, there is labeling of RGCs in the nasal retina, which differentiate prior to those in the temporal retina (Laessing and Stuermer, 1996). By 3 days pf (Fig. 4), a marked decrease in E587 Ag mRNA is evident in most neurons. At this time, most of the tracts have al ready formed. Message persists in the telencephal on (Fig. 4), but most of that seen earlier in nuclei of cranial nerves and el sewhere is hardly detectable at 3 days pf. No labeling was observed with sense probes (not shown).

Wholemount immunohistochemistry was performed on 75-hour pf embryos with an anti-E587 Ag mAb (Fig. 5). These results demonstrate the presence of E587 Ag on all the major axon tracts (Chitnis and Kuwada, 1990; Wilson et al., 1990; Ross et al., 1992). Only the axons and not the cell somata were labeled. A similar staining pattern was observed with an alpha-tubulin antibody (Chitnis and Kuwada, 1990; Wilson et al., 1990), except that moretracts were stained with the E587 Ab (unpublished observation). Although we can no longer detect E587 Ag mRNA in many neurons after 72 hours pf, axons continue to contain a significant amount of E587 Ag on their surface for at least 5 days. Because of the difficulties in breeding and staging goldfish embryos, an extensive study of E587 Ag expression during development is being performed in the zebrafish CNS (Weiland et al., personal communication).

\section{E 587 Ag mRNA expression increases in adult retina following optic nerve transection}

An increase in E587 Ag has been observed on adult retinal axons following ONS (Vielmetter et al., 1991). We used ISH to determine if there was a corresponding upregulation of E587 Ag mRNA in RGCs during axon regeneration. E $587 \mathrm{Ag} \mathrm{mRNA}$ dramatically increases in all RGCs after ONS (Fig. 6). In wholemounts from the normal retina, E587 Ag mRNA was detected in RGCs at the retinal peripheral margin, which is consistent with earlier immunohistochemistry results showing the presence of E $587 \mathrm{Ag}$ on young growing axons that emerge from newborn RGCs added to theretinal margin (Vielmetter et al., 1991) during the continuous growth of the goldfish retina. No labeling was observed with sense probes (Fig. 6). E587 Ag mRNA was not detected in other cell types of the retina, which is in agreement with previous antibody experiments (Viel metter et al., 1991). This expression pattern differs from that of zebrafish L 1.1, which is found not only in RGCs but also in the inner nuclear layer (Bernhardt et al., 1995; Tongiorgi et al., 1995).

In vitro, glial cells from regenerating optic nerves express E587 Ag, and E587 Ag can mediate interactions between growth cones and oligodendrocytes in coculture assays (Bastmeyer et al., 1993). It has been difficult to examine the nonneuronal expression of E587 Ag in the CNS due to the strong axonal staining. Using Reverse Transcription (RT)-PCR, the presence of E587 Ag mRNA in both normal adult optic nerve and in nerve isolated 13 days following ONS was apparent.

\section{DISCUSSION}

The E587 Ag is a cell-recognition molecule capable of mediating axon-axon and axon-glial interactions (Bastmeyer et al., 1993, 1995) and is reexpressed during axonal regeneration (Vielmetter et al., 1991). Here, we identify this molecule as a member of the L 1 family of CAMs and show that its expression is regulated in the CNS during devel opment and in the retina following optic nerve injury.

The identity of the isolated CDNAs as coding for the E587 Ag was confirmed by alignment of the predicted amino acid sequence with those obtained from sequencing E587 Ag peptide fragments. The predicted structure of the E587 Ag is that of a transmembrane protein with extracellular Ig-like and In-like domains. This structure is conserved for all L 1-like proteins including mammalian L 1 (Moos et al., 1988) and Drosophila neuroglian (Bieber et al., 1989). It is not clear whether E587 Ag is the goldfish homologue of any of the previously identified molecules or if it is an additional member of the L 1 family. E587 Ag has the highest degree of identity (65\%) with the zebrafish L1.1 molecule (Tongiorgi et al., 1995). This amount of amino acid identity, however, is low for CAMs that are homologues in these two species. The CAM DM-GRASP was recently cloned in both zebrafish (Kanki et al., 1994) and goldfish (Laessing et al., 1994), and these molecules are $87 \%$ identical at the amino acid level. F urthermore, L 1 in mouse and human are $88 \%$ identical, and avian and mouse N-CAM are $82 \%$ identical. In addition to the relatively low sequence similarity between E587 Ag and zebrafish L 1.1, there are also differences in specific sequence characteristics such as the absence of an RGD sequence in L 1.1 (Tongiorgi et al., 1995). The expression of 

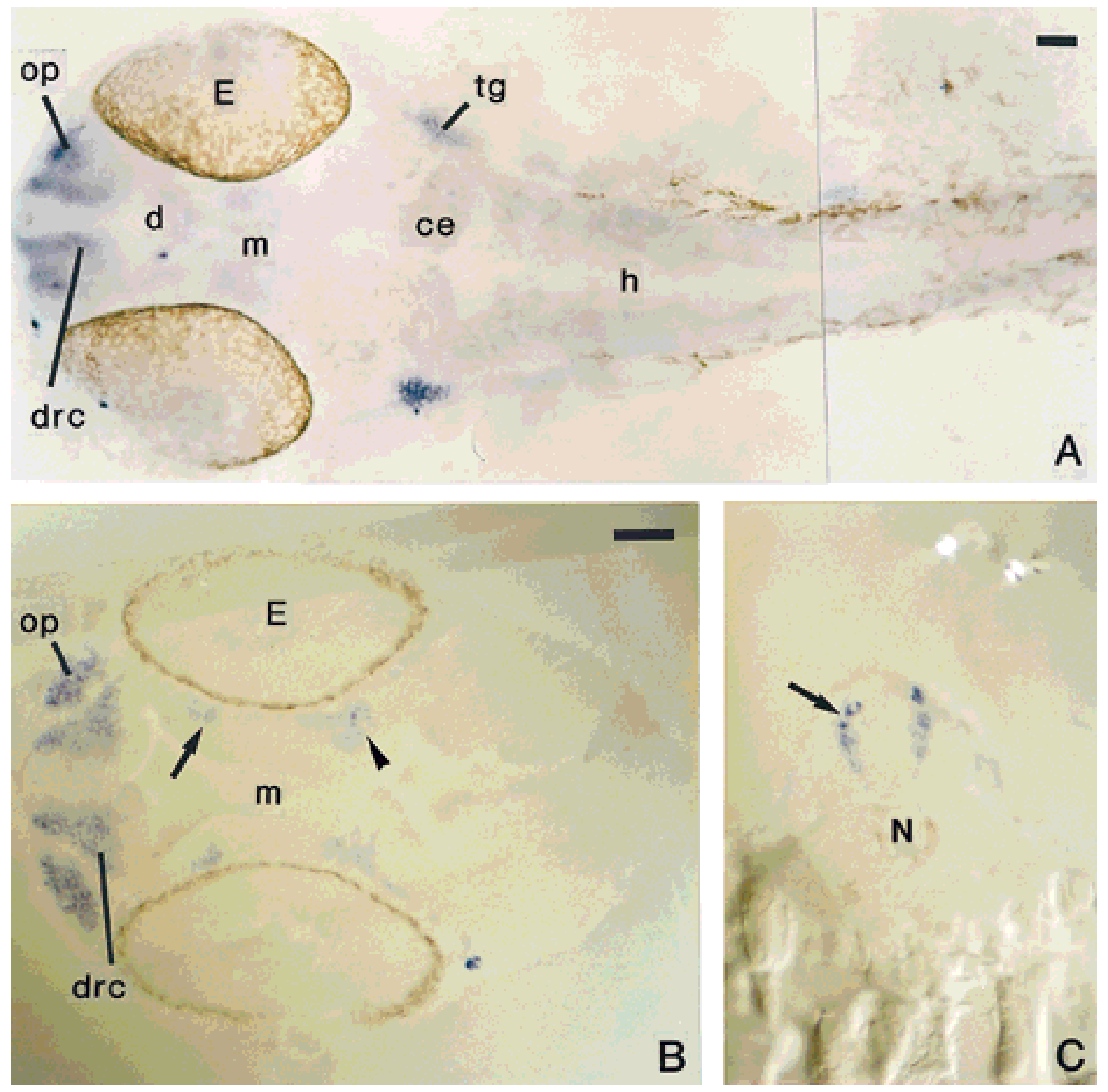

Fig. 3. E587 Ag mRNA expression in 34-hour embryos. A: In situ hybridization signals (embryo wholemount, dorsal view) are most pronounced in the olfactory placode (op), the dorsal rostral cluster in the tel encephal on (drc), from where the axons of the anterior commissure arise, and in neurons of the trigeminal ganglion (tg). More weakly stained are the diencephalic (d) and mesencephalic (m) structures, which are seen more clearly in B, neurons in the hindbrain $(h)$ and in the spinal cord. Retinal ganglion cells in the eye (E) do not yet express E587 Ag mRNA. B: A horizontal section through the head reveals the

both E $587 \mathrm{Ag}$ and zebrafish L1.1 is associated with postmitotic neurons, and both are widely expressed in the embryonic CNS. There are differences, however, in the expression patterns of these two molecules, for example, in the retina. In addition, two messages ( 7 and $8 \mathrm{~Kb}$ ) were detected with E587 $\mathrm{Ag}$ probes by Northern blotting, whereas only one message of $9.5 \mathrm{~Kb}$ was detected for zebrafish L 1.1. These differences may indicate that these cellular localization of the in situ hybridization signal in the op and drc and in the ventral rostral cluster (arrow) in the diencephal on (d) and in the ventral caudal cluster (arrow head) in the mesencephalon (m). C: A cross section through the spinal cord shows signal in neurons that are in lateral positions. The more dorsal neurons (arrow) give rise to commissural axons and those more ventral include (perhaps primary) motor neurons. There is no signal in the floorplate dorsal to the notocord $(\mathrm{N})$. ce: cerebellem. Scale bars $=50 \mu \mathrm{m}$.

molecules are not homologues. A comparison of the functional properties of these molecules may help resolve this issue. A functional analysis of LI.1 and L 1.2 and a description of their protein distributions, however, are not yet available. Because of differences in sequence and expression pattern between chick N g-CAM (Burgoon et al., 1991) and mammalian L 1 (Moos et al., 1988), the relationship of these molecules is also controversial. The compari- 

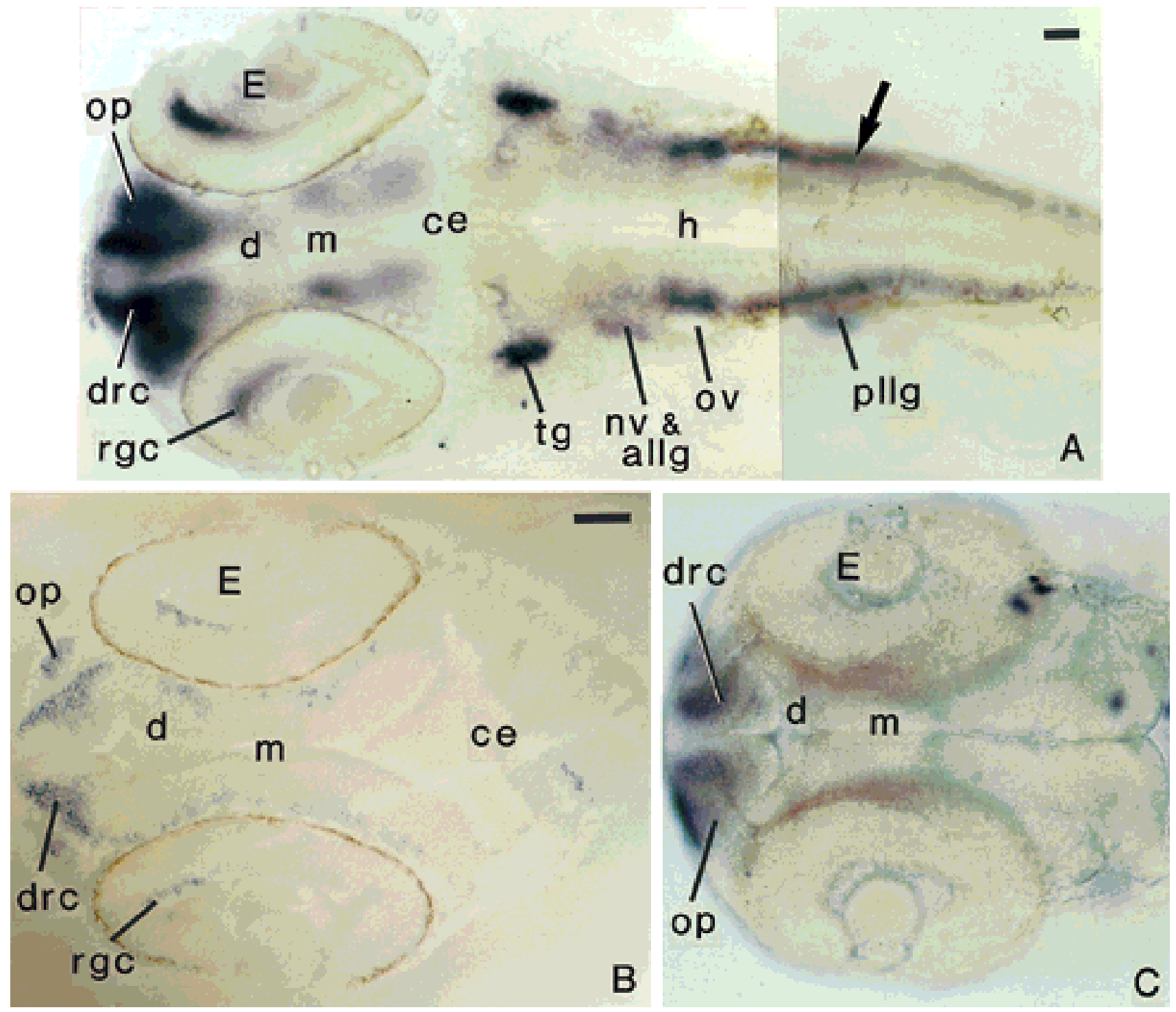

Fig. 4. Increase in E587 Ag mRNA expression in 2-day-old embryos and its decrease at 3 days. A: In situ hybridization signal in 2-day-old embryos (wholemount, dorsal view) are present in many developing neurons. The ol factory placode (op) and the dorsal rostral cluster (drc) are still intensely labeled. Staining extends to more neurons in the diencephal on (d) and mesencephal on ( $m$ ) than was seen at 34 hours postfertilization (pf; Fig. 3) and is present in the cerebellum (ce), and all are more clearly seen in the horizontal section in B. In the eye (E), signal is seen in nasal and dorsal retinal ganglion cells (rgc). In the hindbrain $(\mathrm{h})$, the intensity of staining in the trigeminal ganglion (tg) has also increased, and labeling is still present in neurons of cranial nerve $\mathrm{V}$ (nv) and the anterior lateral line ganglion (allg) and is now also in the posterior lateral line ganglion (pllg). ov, otic vesicle.

son between E587 $\mathrm{Ag}$ and the available $\mathrm{L} 1.2$ sequence (Tongiorgi et al., 1995) shows a lesser degree of similarity than for E587 Ag and L1.1, and therefore L1.2 is most likely another member of the L1 family and not the homologue of goldfish E587 Ag. The E587 Ag, along with L 1.1 and L1.2, may compose a family of L1-like proteins expressed in the fish nervous system. There are other examples of several L 1 family members having overlapping expression patterns. Ng-CAM, Nr-CAM, and neurofas-
Commissural neurons of the hindbrain and spinal cord exhibit the signal and are seen as rows of cells (arrow) in the more peripheral aspect of the central nervous system. B: Horizontal section that shows the cellular localization of mRNA in op, drc, rgcs in the eye (E), in diencephalic (d) and mesencephalic (m) structures, and in the cerebellum (ce). C: In 3-day-old embryos, the olfactory placode (op) and the dorsal rostral cluster (drc) express high levels of E587 Ag mRNA. M ost neurons have downregulated expression of the message, including retinal ganglion cells in the eye $(E)$ and neurons in the diencephal on (d), mesencephalon (m), and cerebellum. This fish was raised in 1-phenyl-2thiourea (PTU) to prevent pigmentation. Scale bars $=50$ $\mu \mathrm{m}$; scale bar in A also applies to C.

cin are all expressed in the embryonic chick CNS, and the expression patterns of these molecules, although not identical, are similar (Thiery et al., 1985; Rathjen et al., 1987; Krushel et al., 1993; Moscoso and Sanes, 1995; Stoeckli and Landmesser, 1995). The coexpression of these L1 family molecules in many embryonic neurons indicates that they have different, al beit overlapping functions.

Of the other vertebrate L 1 family proteins, E587 Ag has the highest identity with mouse L1 (Moos et al., 1988) and 


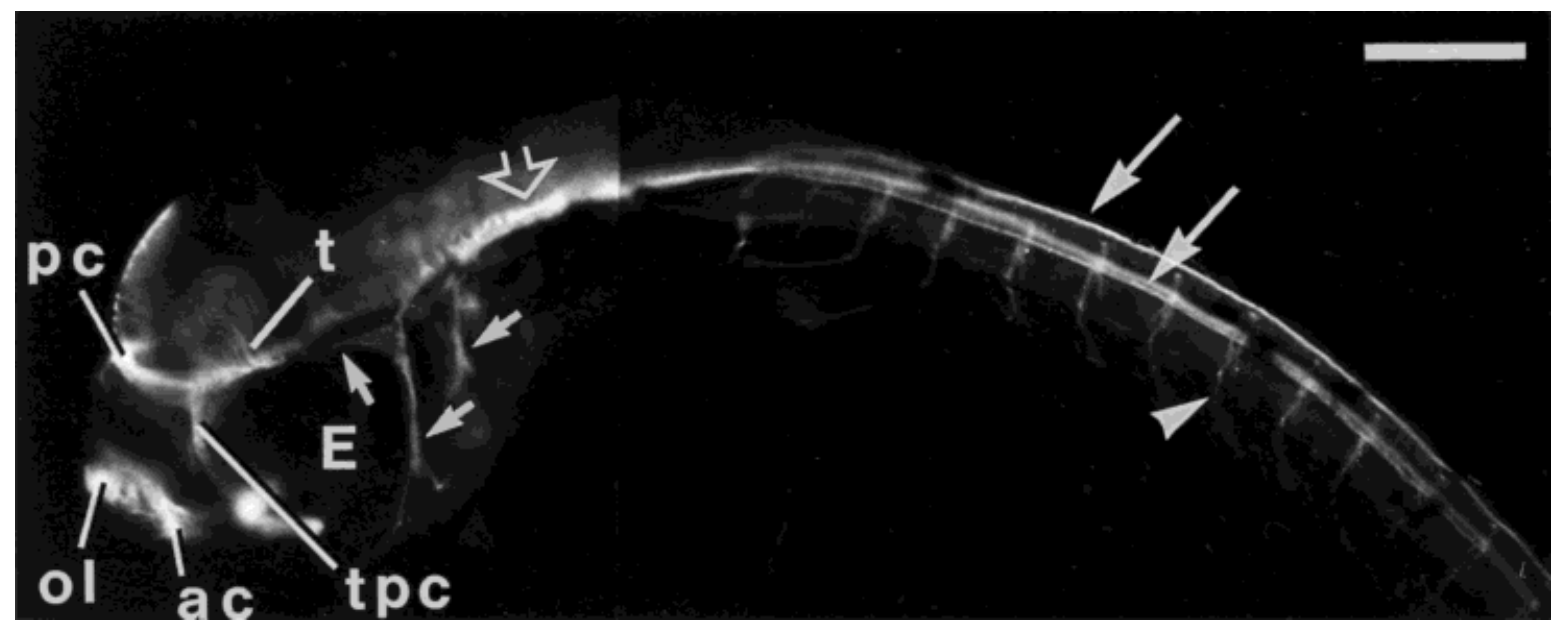

Fig. 5. E587 Ag expression in embryos. Wholemount immunostaining in a 75-hour-pf embryo exemplifies the widespread presence of E587 Ag on axons. E587 Ag is, for instance, present in the olfactory projections (ol), the anterior commissure (ac), the posterior commissure (pc), the tract of the posterior commissure (tpc), the optic nerve (leaving the eye, E), tectal efferent axons (t), branches of the anterior lateral line, trigeminal, and facial nerves (small arrows), the origins of commissural axons (open arrow) in the hindbrain, longitudinal fascicles of the spinal cord (arrows), and axons of motoneurons (arrowhead). Scale bar $=200 \mu \mathrm{m}$. chick Ng-CAM (Burgoon et al., 1991; 42\% and 40\%, respectively). Certain domains of the E587 Ag, however, are more closely related to chick Nr-CAM (Grumet et al., 1991; Table 1). The domains I g-4 and I g-5 of E587 Ag are most related to those domains in chick N g-CAM. E587 Ag I $\mathrm{g}-5$ has $42 \%$ identity with that domain of $\mathrm{Ng}$-CAM but is only $35 \%$ identical to I g-5 of mouse $L 1$ and $25 \%$ identical to that domain in Nr-CAM (Table I). In contrast, domains $\mathrm{Fn}-1$ and $\mathrm{Fn}-2$ of E587 Ag are significantly more related to $\mathrm{Fn}-1$ and $\mathrm{Fn}-2$ of Nr-CAM (52\% and $50 \%$ ) than those of $\mathrm{Ng}$-CAM (36\% and 45\%) or L 1 (44\% and 42\%), whereas domains $\mathrm{F} \mathrm{n}-3$ and $\mathrm{Fn}-4$ of $\mathrm{E} 587 \mathrm{Ag}$ are closest in sequence to those domains in mouse L 1 . Therefore, it is not possible from this analysis to classify E587 Ag as a definitive homologue of one of the previously identified members of the L 1 family.

A comparison between the amino acid sequences of $L 1$ family members reveals regions that are very highly conserved. The high conservation of certain domains suggests that these may be functionally important. The cytoplasmic domain in particular contains long stretches of amino acids that are identical in all members of the L 1 family. These molecules may all be able to interact with similar cytoplasmic components. Interactions with the cytoskeleton and with molecules of signal transduction pathways have been demonstrated for $L 1$ or $L 1$ family members (Doherty and Walsh, 1992; Gumbiner, 1993; Rakic et al., 1994). One conserved region has been implicated in ankyrin binding (Davis et al., 1993). Ll is phosphorylated by casein kinase II (CKII; Wong et al., 1996), and this CKII phosphorylation site is also found in the E 587 Ag (aa 1145). In some cases, L 1 may al so mediate axonal growth through interactions with the pp60src signaling pathway (Ignelzi et al., 1994). Furthermore, recent results implicate a conserved region in the fourth Ig domain, also present in the E587 Ag, in interacting with the fibroblast growth factor (FGF) receptor to stimulate signal transduction pathways (Williams et al., 1994).

These molecules are often called neural CAMs; however, some members of $L 1$ family are al so expressed by nonneu- ronal cells and can mediate interactions between these cells and other cells or axons (Grumet, 1992; Kayem et al., 1992). Previous in vitro results have indicated that E587 $\mathrm{Ag}$ is present on cultured glia and mediates axon-glial interactions (Bastmeyer et al., 1993). Results presented here suggest that E $587 \mathrm{Ag}$ is al so expressed by nonneuronal cells in the optic nerve. The described axon-glia interactions involving E587 Ag could therefore occur through homophilic or heterophilic binding. Nr-CAM and neurofascin are also expressed by nonneuronal cells, and neur ofascin, like the E $587 \mathrm{Ag}$, is found on oligodendrocytes (Moscoso and Sanes, 1995). In some cases, nonneuronal cells may express a splicing variant of the $L 1$ protein in addition to or instead of the complete L1 (Miura et al., 1991). This splice variant lacks the four amino acid residues RSLE in the cytoplasmic tail. The consequence of this splicing is not known but also occurs in other L1 family members (Miura et al., 1991; Moscoso and Sanes, 1995). In the goldfish, this sequence is altered by a conservative change to KSLE. We found no evidence of a splicing variant for E587 Ag CDNAs isolated from the optic nerve. All clones obtained contain theKSLE sequence. The splicing form lacking the four amino acids may not exist in the E587 Ag or may below.

Fig. 6. Expression of E587 Ag mRNA in retinal ganglion cells (RGCS). A: In a retina wholemount, isolated from a normal fish, the only cells expressing E587 Ag mRNA are ganglion cells more recently added to the retinal margin (arrowheads). od, optic disk. B: In this retina whol emount, isolated 14 days following optic nerve transection, most or all retinal ganglion cells strongly express the E587 Ag mRNA. The typical organization of retinal ganglion cells in rows that are separated by retinal axons is apparent. C: Higher magnification of E587 Ag mRNA expressing ganglion cells at the retinal margin. Arrows point to individual ganglion cells. D: Higher magnification of E $587 \mathrm{Ag}$ mRNA reexpressing ganglion cells (some of which are marked by arrows) of the retina 14 days after optic nervetransection (shown in B). Axon bundles running between the rows of ganglion cells are indicated (ax). E: Hybridization with sense probes are blank. This figure was computer generated by using Adobe Photoshop through Scale bar $=200 \mu \mathrm{m}$ for $\mathrm{A}, \mathrm{B}, \mathrm{E}, 20 \mu \mathrm{m}$ for C, D. 


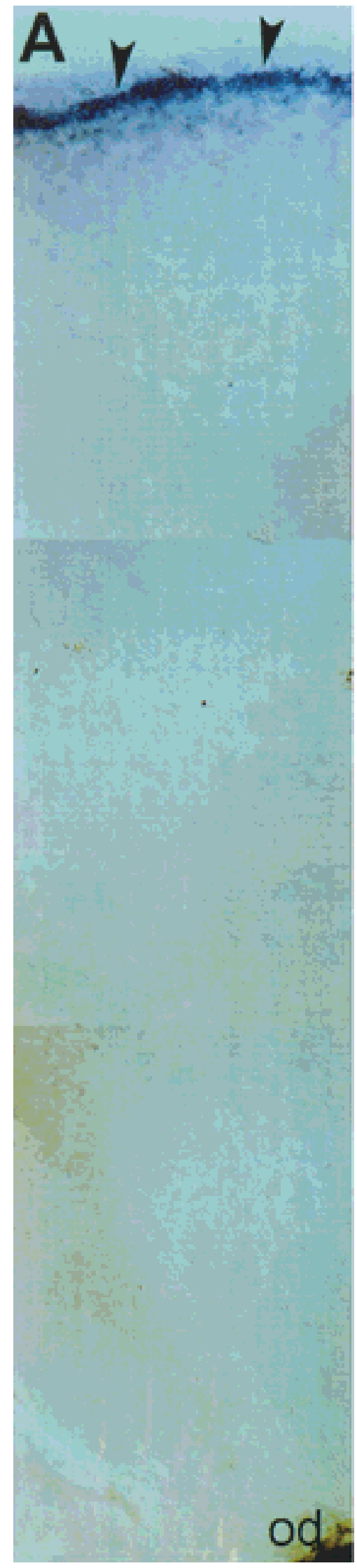

\section{B}

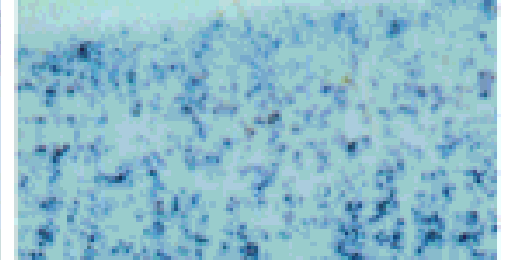

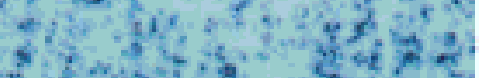

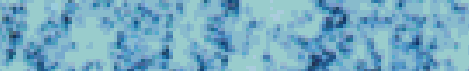

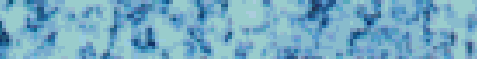

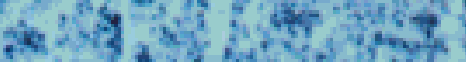

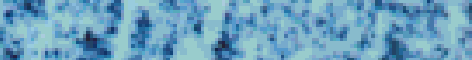

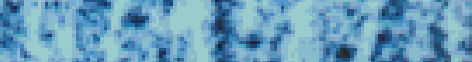
$x^{2}+3 \mathrm{~g}^{2}$.

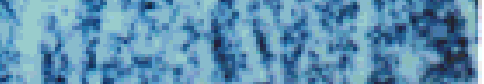

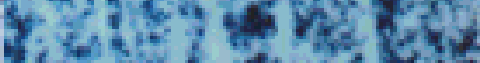

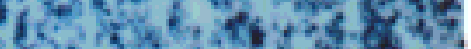

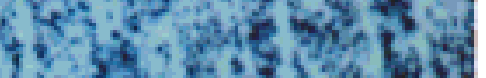

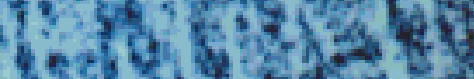

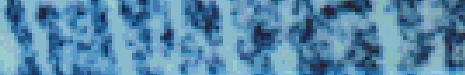

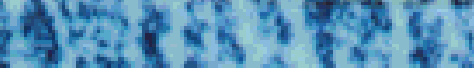

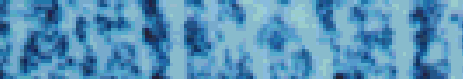

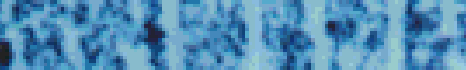

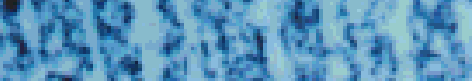

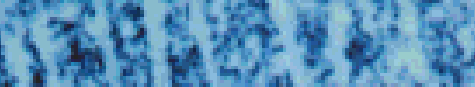

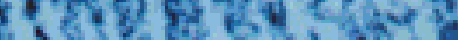

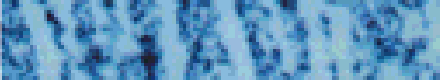
b.

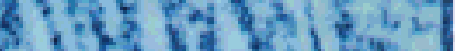

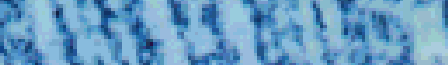

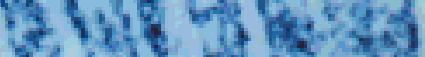

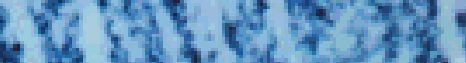

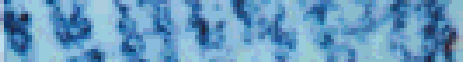

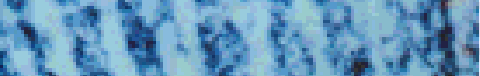

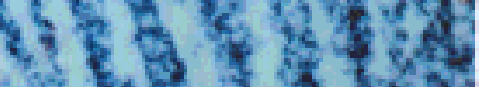

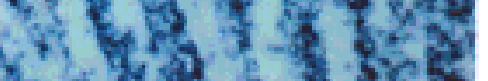

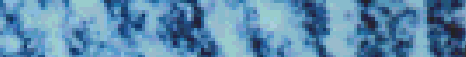

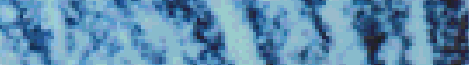

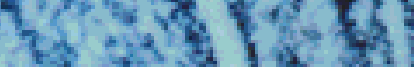

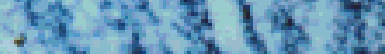
$+x^{2}, z^{2}, \frac{3}{2}$
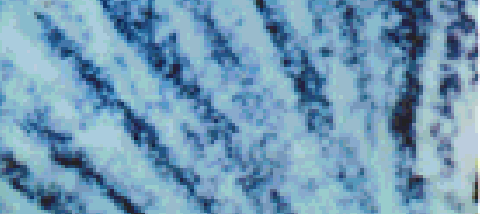

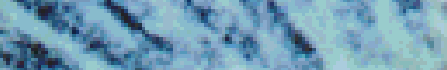

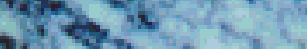

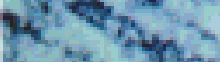

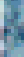

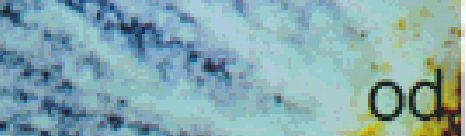

C
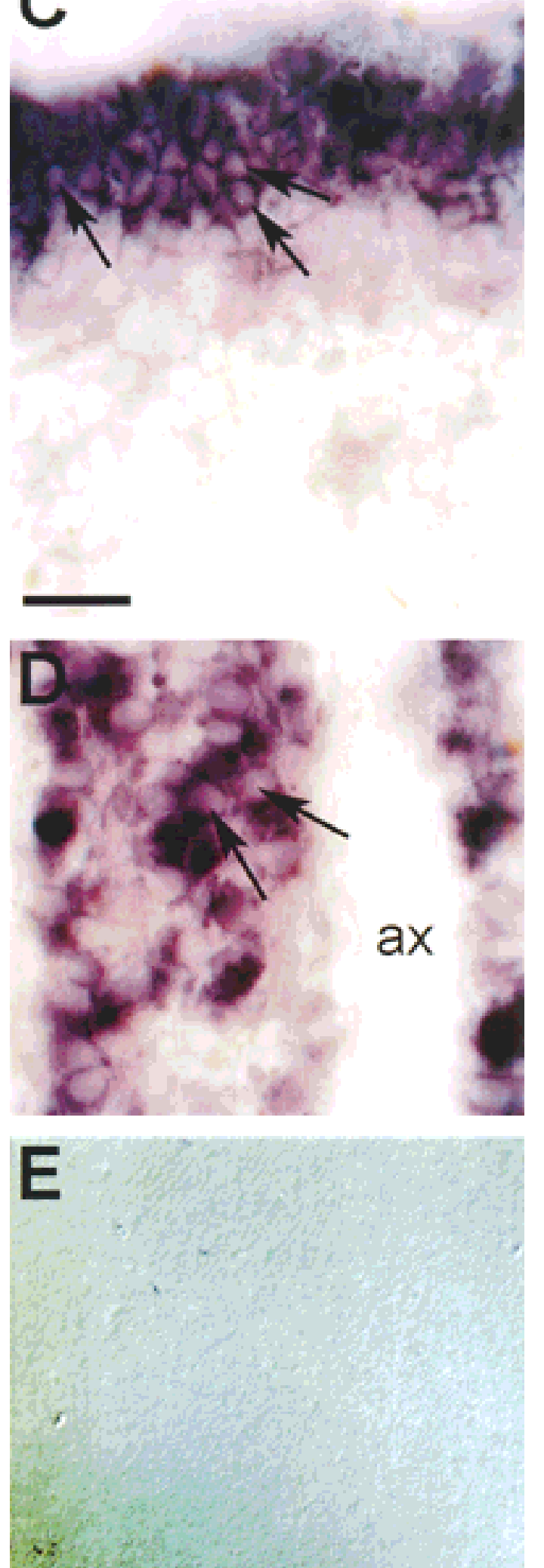
CAMs not only interact homophilically but participate in complex heterophilic interactions (Brümmendorf et al., 1993; Felsenfeld et al., 1994). In the chick spinal cord, $\mathrm{Ng}$-CAM interacts with other $\mathrm{Ng}$-CAM molecules, whereas $\mathrm{Nr}$-CAM interacts heterophilically with axonin-1, which belongs to another family of Ig-like CAMs (Stoeckli and L andmesser, 1995). These interactions have distinct functional consequences resulting in fasciculation or in axonal guidance. Furthermore, interactions between N-CAM and L1 in the same cell can modulate L1-L1 interactions on opposing cells (Kadmon et al., 1990). Several CAMs in addition to $E 587 \mathrm{Ag}$ have been identified in the fish CNS, including neurolin, the homologue of chick DM-GRASP/ Ben/SCl (Kanki et al., 1994; Laessing et al., 1994), and $\mathrm{N}$-CAM (Bastmeyer et al., 1990) in the goldfish, and Tag-1/axonin-1 (Warren et al., 1995) and L1.1 and L1.2 (Tongiorgi et al., 1995) in the zebrafish. Therefore, several Ig-like CAMs with overlapping patterns of expression are present in the fish CNS. It will now be possible to investigate the functions of these molecules and if interactions between different CAMS can alter these functions during CNS development. Furthermore, the capacity for regeneration in the fish and the upregulation of E587 Ag following optic nerve lesion allows for the study of how CAMs are regulated during CNS injury and how they participatein axon regeneration.

\section{ACKNOWLE DGMENTS}

This work was supported by SFB 156 to C.A.O.S. S.G. was supported in part by the Alexander von HumboldtFoundation. R.A. is a fellow of the Boehringer-IngelheimFonds.

We thank Ulrike Binkle for excellent technical assistance and UIrich Weiland and Thomas Schulte for their assistance with the immunohistochemistry. We are grateful toAnnette-Yvonne Loos for the care and breeding of the goldfish and to Mary Ann Cahill for assistance with the figures.

\section{LITERAT URE CITE D}

Bastmeyer, M., B. Schlosshauer, and C.A.O. Stuermer (1990) The spatial distribution of N-CAM in the retinotectal pathway of adult goldfish detected by the monoclonal antibody D3. Devel opment 108:299-311.

Bastmeyer, M., M. Bähr, and C.A.O. Stuermer (1993) Fish optic nerve oligodendrocytes support axonal regeneration of fish and mammalian retinal ganglion cells. Glia 8:1-11.

Bastmeyer, M., H. Ott, C.A. Leppert, and C.A.O. Stuermer (1995) Fish E587 glycoprotein, a member of the L1 family of cell adhesion molecules, participates in axonal fasciculation and the age-related order of ganglion cell axons in the gol dfish retina. J. Cell Biol. 130:1-9.

Bernhardt, R.R., E. Tongiorgi, and M. Schachner (1995) Up-regulation of recognition molecules during the successful regeneration of the fish optic pathway. Soc. Neurosci. Abstr. 21:1276.

Bieber, A.J ., P.M. Snow, M. Hortsch, N.H. Patel, J .R. J acobs, Z.R. Traquina, J.Schilling, and C.S. Goodman (1989) Drosophila neuroglian a member of the immunoglobulin superfamily with extensive homology to the vertebrate neural adhesion molecule L1. Cell 59:447-460.

Brümmendorf, T., and F.G. Rathjen (1993) Axonal glycoproteins with immunoglobulin- and fibronectin type III-related domains in verte brates: structural features, binding activities, and signal transduction. J. Neurochem. 61:1207-1219.

Brümmendorf, T., M. Hubert, U. Treubert, R. Leuscher, A. Tarmok, and F.G. Rathjen (1993) The axonal recognition molecule F11 is a multifunctional protein: specific domains mediate interactions with $\mathrm{Ng}$-CAM and restrictin. Neuron 10:711-727.

Burgoon, M.P., M. Grumet, V. Mauro, G.M. Edelman, and B.A. Cunningham (1991) Structure of the neuron-glia cell adhesion molecule, $\mathrm{Ng}$ -
CAM: Origin of the polypeptides and relation to the Ig superfamily. J . Cell Biol. 112:1017-1029.

Chitnis, A.B., and J.Y. Kuwada (1990) Axonogenesis in the brain of zebrafish embryos. J . Neurosci. 10:1897-1905.

Davis, J., T. McLaughlin, and V. Bennett (1993) Ankyrin-binding proteins related to nervous system adhesion molecules: Canidates to provide transmembrane and intercellular connections in adult brain. J . Cell Biol. 121:121-133.

Doherty, P., and F. Walsh (1992) Cell adhesion molecules, second messengers and axonal growth. Curr. Opin. Neurobiol. 2:595-601.

Easter, S.S. J r., B. Bratton, and S.S. Scherer (1984) Growth-related order of the retinal fiber layer in goldfish. J . Neurosci. 4:2173-2190.

Felsenfeld, D.P., M.A. Hynes, K.M. Skoler, A.J . Furley, and T.M. J essel (1994) TAG-1 can mediate homophilic binding but neurite outgrowth on TAG-1 requires an L1-like molecule and $\beta 1$ integrins. Neuron 12:675690.

Grumet, M. (1992) Structure expression and function of Ng-CAM, a member of the immunoglobulin superfamily involved in neuron-neuron and neuron-glia adhesion. J . Neurosci. Res. 31:1-13.

Grumet, M., V. Mauro, M.P. Burgoon, G.M. Edelman, and B.A. Cunningham (1991) Structure of a new nervous system glycoprotein $\mathrm{Nr}$-CAM and its relationship to subgroups of neural cell adhesion molecules. J . Cell Biol. 113:1399-1412.

Gumbiner, B.M. (1993) Proteins associated with the cytoplasmic surface of adhesion molecules. Neuron 11:551-564.

Hynes, R.O. (1987) Integrins: A family of cell surface receptors. Cell 48:549-554.

Ignelzi, M.A., D.R. Miller, P. Soriano, and P.F. Maness (1994) Impaired neurite outgrowth of src-minus cerebellar neurons on the cell adhesion molecule L1. Neuron 12:873-884.

Kadmon, G., A. Kowitz, P. Altevogt, and M. Schachner (1990) The neural cell adhesion molecule N-CAM enhances L1-dependent cell-cell interactions. J . Cell Biol. 110:193-208.

Kanki, J .P., S. Chang, and J .Y. Kuwada (1994) The molecular cloning and characterization of potential chick DM-grasp homologs in zebrafish and mouse. J . Neurobiol. 25:831-845.

Kayem, J.F., J.M. Roman, E.J . de la Rosa, U. Schwarz, and W.J . Dreyer (1992) Bravo/ $\mathrm{Nr}$-CAM is closely related to the cell adhesion molecules L1 and $\mathrm{Ng}$-CAM and has a similar heterodimer structure. J. Cell Biol. 118:1259-1270.

Krushel, L.A., A.L. Prieto, B.A. Cunningham, and G.M. Edelman (1993) Expression patterns of the cell adhesion molecule $\mathrm{Nr}$-CAM during histogenesis of the chick nervous system. Neuroscience 53:797-812.

Lemmon, V., K.L. Farr, and C. Lagenaur (1989) L1-mediated axon outgrowth occurs via a homophilic binding mechanism. Neuron 2:15971603.

Laessing, U., and C.A.O. Stuermer (1996) Spatiotemporal pattern of retinal ganglion cell differentiation revealed by the expression of neurolin in embryonic zebrafish. J . Neurobiol. 29:65-74.

Laessing, U., S. Giordano, B. Stecher, F. Lottspeich, and C.A.O. Stuermer (1994) Molecular characterization of fish neurolin: A growth associated cell surface protein and a member of the immunoglobulin superfamily in the fish retinotectal system with similarities to chick protein DM-GRASP/SC-1/BEN. Differentiation 56:21-29.

Moos, M., R. Tacke, H. Scherer, D. Teplow, K. Früh, and M. Schachner (1988) Neural cell adhesion molecule L1 is a member of the immunoglobulin superfamily with binding domains similar to fibronectin. Nature 334:701-703.

Moscoso, L.M., and J .R. Sanes (1995) Expression of four immunoglobulin superfamily adhesion molecules ( $\mathrm{L} 1, \mathrm{Nr}$-CAM/Bravo, Neurofascin/ ABGP, and N-CAM) in the developing mouse spinal cord. J . Comp Neurol. 352:321-334.

Miura, M., M. Kobayashi, H. Asou, and K. Uyemura (1991) Molecular cloning of CDNA encoding the rat neural cell adhesion molecule L 1: Two L1 isoforms in the cytoplasmic region are produced by differential splicing. FEBS 289:91-95.

Rakic, P., R.S. Cameron, and H. Komuro (1994) Recognition, adhesion, transmembrane signaling and cell motility in guided neuronal migration. Curr. Opin. Neurobiol. 4:63-69.

Rathjen, F.G., J .M. Wolff, S. Chang, F. Bonhoeffer, and J .A. Raper (1987) Neurofascin: A novel chick cell-surfaceglycoprotein involved in neuriteneurite interactions. Cell 51:841-849.

Rosenthal, A., R.N. Mackinnon, and C. J ones (1991) PCR walking from microdissection clone M54 identifies three exons from the human gene for the neural cell adhesion molecule L1. NAR 19:5395-5401. 
Ross, L.S., T. Parrett, and S.S. Easter (1992) Axonogenesis and morphogenesis in the embryonic zebrafish brain. J . Neurosci. 12:467-482.

Sonderegger, P., and F.G. Rathjen (1992) Regulation of axonal growth in the vertebratenervous system by interactions between glycoproteins belonging to two subgroups of the immunoglobulin superfamily. J . Cell Biol. 119:1387-1394.

Stallcup, W.B., L. Beasley, and J . Levine (1985) Antibody against nerve growth factor-inducible large external (NILE/L1) glycoprotein labels nerve fiber tracts in the developing rat nervous system. J . Neurosci. 5:1090-1101.

Stoeckli, E., and L.T. Landmesser (1995) Axonin-1, Nr-CAM and Ng-CAM play different roles in the in vivo guidance of chick commissural neurons. Neuron 14:1165-1179.

Stuermer, C.A.O., M. Bastmeyer, M. Bähr, G. Strobel, and K. Paschke (1992) Trying to understand axonal regeneration in the CNS of the fish. J. Neurobiol. 23:537-550.

Thiery, J.P., A. Delouvee, M. Grumet, and G.M. Edelman (1985) Initial appearance and regional distribution of the neuon-glia cell adhesion molecule in the chick embryo. J . Cell Biol. 100:442-446.

Tongiorgi, E., R.R. Bernhardt, and M. Schachner (1995) Zebrafish neurons express two L1-related molecules during early axonogenesis. J . Neurosci. Res. 42:547-561.

Vielmetter, J ., F. Lottspeich, and C.A.O. Stuermer (1991) The monoclonal antibody E 587 recognizes growing (new and regenerating) retinal axons in the goldfish retinatectal pathway. J . Neurosci. 11:3581-3593.

Volkmer, H., B. Hassel, J.M., Wolf, R. Frank, and F.G. Rathjen (1992) Structure of the axonal surface recognition molecule neurofascin and its relationship to a neural subgroup of the immunoglobulin superfamily. J. Cell Biol. 118:149-161.

Warren, J .T., J .P. Kanki, R. Rangarajan, A. Furely, and J .Y. Kuwada (1995) Molecular cloning and expression analysis of zebrafish TAG-1. Soc. Neurosci. Abstr. 21:533.

Wilson, S.W., L.S. Ross, T. Parrett, and S.S. Easter (1990) The development of a simple scaffold of axon tracts in the brain of the embryonic zebrafish, Brachydanio rerio. Development 180:121-145.

Williams, E.J ., J . Fumes, F.S. Walsh, and P. Doherty (1994) Activation of the FGF receptor underlies neurite outgrowth stimulated by L1, N-CAM and $\mathrm{N}$-cadherin. Neuron 13:583-594.

Wong, E.V., A.W. Schaefer, G. Landreth, and V. Lemmon (1996) Casein kinase II phosphorylates the neural cell adhesion molecule L1. J. Neurochem. 66:779-786. 